\title{
SIZE DISTRIBUTION OF PELAGIC FISHES IN THE JAVA SEA BY MEANS OF TARGET STRENGTH ANALYSIS
}

\author{
Bambang Sadhotomo \\ Research Institute For Marine Fisheries, Muara Baru-Jakarta
}

Received July 13-2007; Received in revised form August 30-2007; Accepted Sept 4-2007

\begin{abstract}
This study aims to provide information on spatial distribution of fish size of pelagic community in the Java Sea. It was based on target strength data observed during the acoustic cruises made by Research Vessel Bawal Putih in the years 1992 until 1994 and October 2005, using dual beam and split beam echosounder operated at $120 \mathrm{Khz}$. The data were analysed descriptively by performing single regression and graphical presentation. A gradient of fish size was obviously indicated in the middle and northen part of the Java Sea, while random pattern was clearly observed in the north coast of Madura-Flores waters. These implied that migratory routes existed in west northeast axis, from Karimunjawa to Matasiri Bank. Most of the pelagic fishes tended to stay and spend part of their life span in the Java Sea. The results implied that only part of the stock(s) were exploited by the fisheries.
\end{abstract}

KEYWORDS: $\quad$ target strength, pelagic fish, Java Sea

\section{INTRODUCTION}

During the first three decades of this century, observations on fish size distribution in the Java Sea had been done as part of oceanographic research. Based on those observations, Hardenberg (1938) built a hypothesis on the Decapterus populations and its migration. Recently, based on intensive length measurement data, a more comprehensive hypothesis was proposed in the context of migration and recruitment (Potier \& Sadhotomo, 1995). It maybe stated that the javanese seiner fishery exploits only part of the stock (s) in the Java Sea. However, knowledge of geographical repartition is important, especially in relation with partition of exploited stocks. In general, for many migratory fish spatial feature of size distribution relates to the life history. It can be pointed out that the importance of a study in this domain is apparent, especially to underlie an estimation of abundance and biological parameters as well as in modelisation of population change. If this is the case, ignoring spatial feature of size distribution in fish abundance estimation may lead to substantial biases.

It has been recognized that fluctuation of pelagic fish abundance in the Java Sea associating with seasonal change of hydrographic characters. Justified by this fact, evaluation on the ecological aspects will involve these variations. In the area of the Java Sea, fishery data were usually used to explain fluctuation of pelagic abundance and their relation to climatic parameter, for example, the investigations conducted by Potier \& Boely (1990).

As consequence of operational aspect exerted in the fishery, the evolution of the catch and catch per unit of nominal effort exhibited in the same pattern (Sadhotomo \& Widodo, 1994; Potier, 1998). In this case, vulnerability to the fishery could be assumed to be proportional to the abundance. A complete absence of fishing fleet in certain month in the areas around Kangean Island and Southern of the South China Sea could generate an under estimate but since the fleet operated in fishing areas inside the Java Sea tends to be, oportional to the concentration of shoal as mentioned previously (Potier \& Sadhotomo, 1995), the seasonal abundance of pelagic fish by fishing zones would fluctuate in the same trend as catch composition derived from the fishery data. This study is a synthesis of information generated from exploratory survey data collected during the Java Sea pelagic fishery assessment project (1991 until 1997) and the recent data (during inhouse project in 2005). Preliminary information had been published elsewhere during the project running (see Potier \& Nurhakim (eds), 1995).

This study attempted to evaluate size distribution of the pelagic species by exploring target strength data collected during the acoustic survey. Still in the frame of the context of this study, this paper dealed with ecological behaviour of the pelagic community in the Java Sea, and consists of spatial distribution of fish size and its relation to migration. 


\section{MATERIALS AND METHODS}

Based on the origin of the data sources, this paper consists of merely target strength data observed during the cruise of Research Vessel Bawal Putih. No particular analysis was performed and sources of information used in this paper were merely derived from the acoustic survey data of Research Vessel Bawal Putih collected during three acoustics cruises on June 1992, October 1993, February 1994, and October 2005. The survey data were composed of the individual acoustic characteristics of the fish size as observed by using the dualbeam vertical echo sounder (Biosonic 120'S) for data collected in 1992 until 1994 and the split beam sounder (Simrad EK 60s) for more recent data obtained in the year 2005. The sounders operated at $120 \mathrm{Khz}$.

This study deals only with the utilisation of certain part of the acoustic data collected during acoustic cruises of Research Vessel Bawal Putih. The first cruise was made on June 1992, at the beginning of the recruitment of pelagic fishes in the Java Sea. The others were carried out on October 1993, February 1994, and October 2005, covering most of central and eastern parts of the Java Sea and western part of the Flores Sea (Figure 1). These cruises would represent the conditions during Southeast and Northwest monsoon. The information content of the data were the date, time, position, and digitized signal received by echosounder. A type of acoustic measurement that usually used for individual size measurement of target strength, was recorded in certain period of time (e.g. about 10 minute) for the 1992, 1993, and 1994 data in some positions along the tracks in dualbeam sounder (Biosonic 102 type), while the newer sounder, splitbeam Simrad EK 60s did continously for a file (for 2005 data).

Vertical salinity and temperature profile measurements were carried out during the cruise. The location of stations could be assumed to be the same as the position of the target strength observation. The probes (Seabird) were lowered to the water when the boat being stopped for allowing to save the target strength measurement. Salinity and temperature were recorded continously following the depth. Evaluation on the relationship between some environmental feature (salinity, depth, and position) and spatial distribution of size will be attempted by employing the target strength data recorded during the October 1993 and February 1994 cruises covering two dimensional transect.

In order to find a possible relationship between size distribution and physical and environmental variability, exploratory schemes were performed to the target strength frequency data with emphasizing on the size distribution by spatial gradient (i.e. longitude, depth) and salinity. It involved fitting simple linear regression and plotting which allow us to identify possible influence of depth, salinity, and longitude. Arbitrary defined one degree intervals of longitude are intended to be corresponding to east west axis direction.

Also, some structural characteristics (of density) seem to stay constant, from one season to the other, and during one season (Petit \& Potier, 1995). In order to give a general description on the influence of depth strata, could be performed in two schemes for describing the target strength distribution by depth layers, i.e. by plotting the mean target strength versus average depth at each layer, and depicting the horizontal distribution at various depth layers. Other arbitrary depth layers were defined as 2 to $32 \mathrm{~m}, 32$ to $52 \mathrm{~m}$, and more than $52 \mathrm{~m}$. However, assumption could be put that variance of target strength values inside an interval was more uniform than that between other ones. Mean of target strength were calculated as mode of pooled data for avoiding the bias due to decibel unit of measurement used in target strength (i.e. calculating means on logarithmic values). 
October 1993

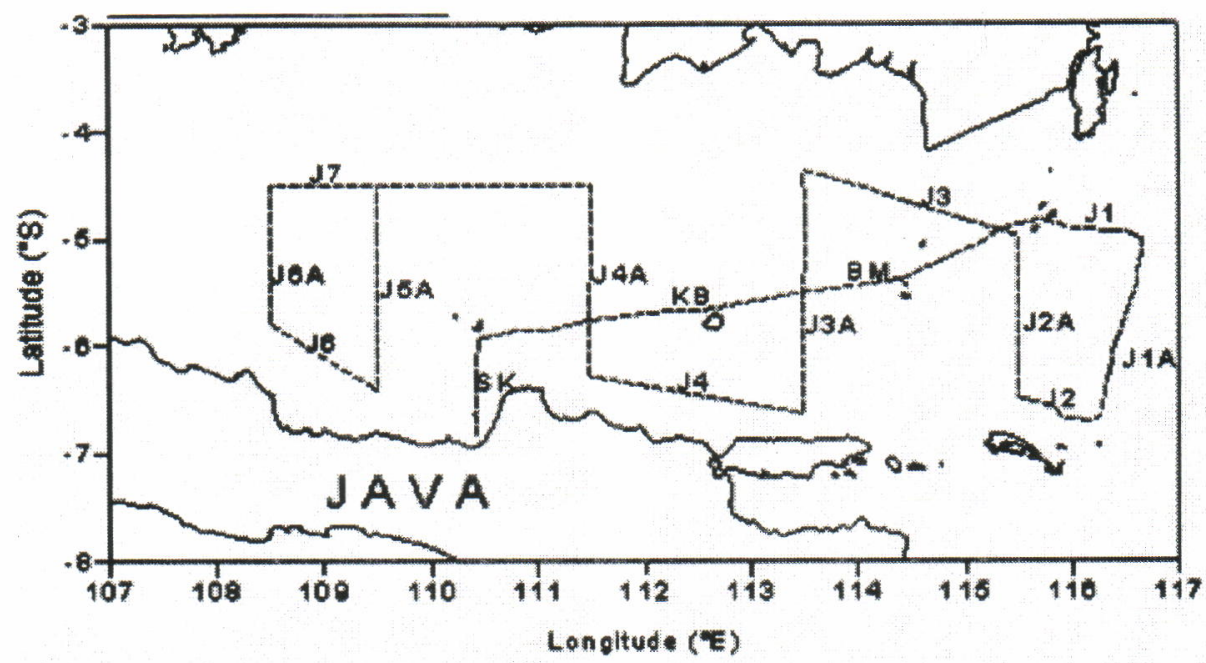

February 1994

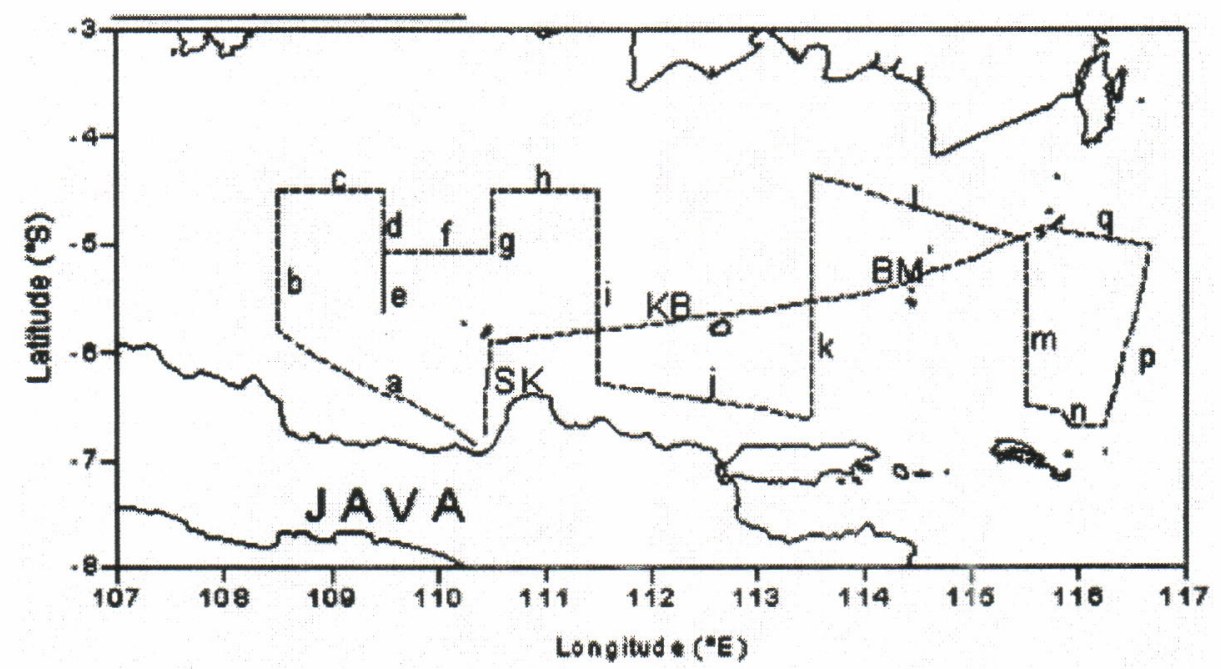

October 2005

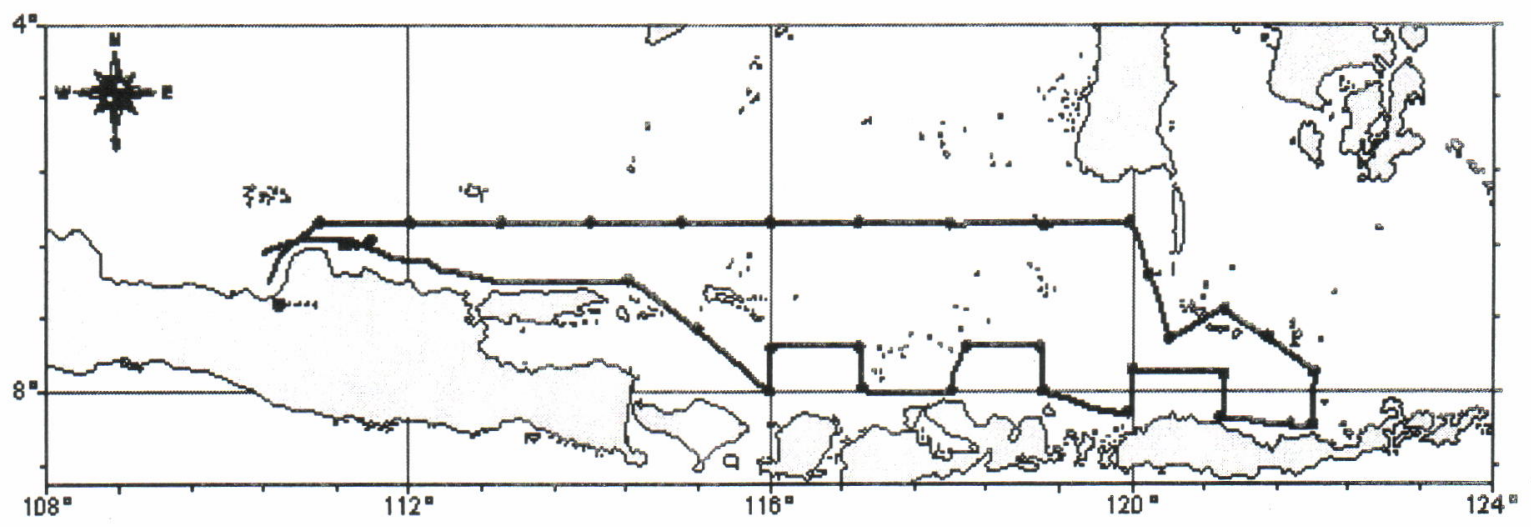

Figure 1. Selected tracts used for analysis. 


\section{RESULTS and DISCUSSION}

A general description on the seasonal abundance of fish, since this phenomenon can be assumed as reflection of the response of pelagic community to environment variability. In general, a shifting of abundance was markedly shown by the change of the peaks of the indices for the areas extended from north of central Java to Lumu-lumu Island and Flores Sea in the Southernmost of Macassar Strait (Sadhotomo \& Potier, 1995). As previously shown, a tendency to occupy different places according to size category was obviously observed, but there was no measurement made outside of the fishing zones. On the other hand, coverage of the target strength observations were more continuous, i.e. along two dimensional transects covering part of the Java Sea area extending from north of central Java to Matasiri Island conducted on October 1993, February 1994, and October 2005. The use of target strength measurement in this study was emphasized in topics of longitudinal gradient in target strength distribution and its relation to salinity, gradient and depth. An interpolation procedure was employed for pooling the target strength observations from the stations close to the salinity stations, in order to obtain a new data set consist of the target strength value correspond to the salinity observation. However, repartition of the mean target strength was less homogeneous in one degree interval, eventhough this was based on rough graphical presentation

\section{Target Strength Vs Depth}

The measurements were set into several layers depth with $10 \mathrm{~m}$ interval beginning from 2 to $12 \mathrm{~m}$ deep as the first layer. The distribution of target strength values at each depth interval can be seen in Figure 2. The tendency that the increase of target strength with depth was identical within for all cruise. Slight differences are indicated by observations carried out in rainy season. Strong influence of depth on target strength was obviously shown by high coefficient of regression and the pattern of plotting for all seasons. Slight differences in regression coefficient are also exhibited by the data from straight transect from Karimunjawa to Matasiri Bank (Table 1).
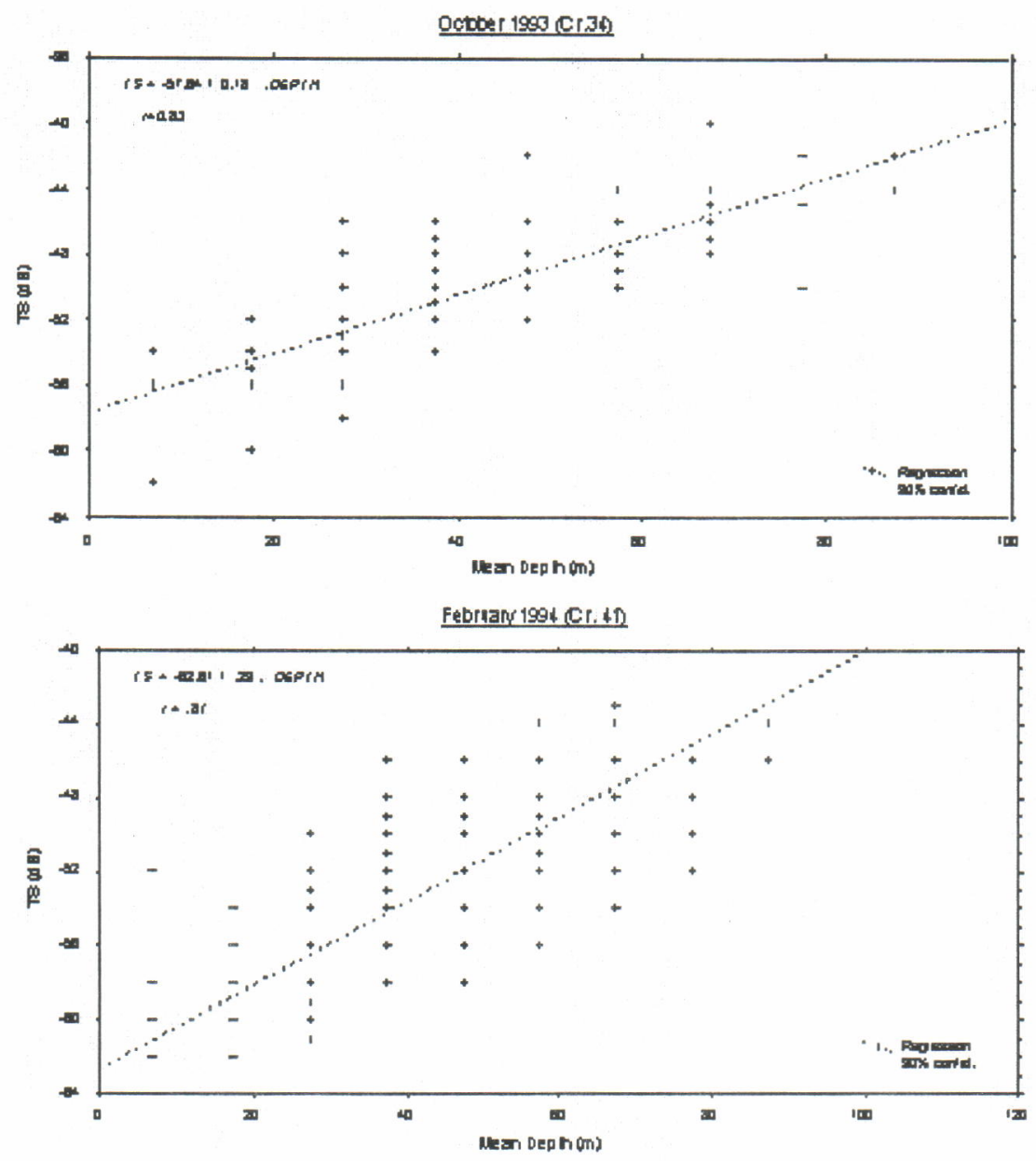

Figure 2. Relation between mean depth of each layer and target strength of two selected cruises. 
Table 1.

Simple regression of target strength on depth

\begin{tabular}{|c|c|}
\hline Date and area covered & $T S=a+b_{1}$, depth \\
\hline $\begin{array}{l}\text { October 1993: } \\
\text { Karimunjawa-Matasiri bank: }\end{array}$ & $\begin{array}{lll}a=-60.9 ; & b=0.22 ; & r=0.81 \\
a=-60.4 ; & b=0.21 ; & r=0.78\end{array}$ \\
\hline $\begin{array}{l}\text { February } 1994 \text { (all): } \\
\text { Karimunjawa-Matasiri bank: }\end{array}$ & $\begin{array}{lll}a=-62.6 ; & b=0.22 ; & r=0.87 \\
a=-62.4 ; & b=0.22 ; & r=0.85\end{array}$ \\
\hline $\begin{array}{l}\text { October 2005: Madura-Flores: } \\
\text { October 1993: Karimunjawa-Matasiri: }\end{array}$ & $\begin{array}{lll}a=-57.6 ; & b=0.18 ; & r=0.83 \\
a=-57.4 ; & b=0.18 ; & r=0.81\end{array}$ \\
\hline
\end{tabular}

There are two possible factors, which may have an impact on the target strength values:

1. The first one was biological factor. In this case the results would demonstrate the preference of bigger fish to occupy the deeper layer for particular pelagic species.

2. The second factor was an artifact of acoustic phenomenon. Theoretically, this bias may exist and had been observed in the most of the acoustics projects in the world (Midttun, 1984; Ona, 1984; Mukai \& Foote, 1997) and in this case as indicated by experimental measurement using dual beam with one species (Cotel \& Petit, 1995). In the deeper layer, the coverage of the beam or beam width are larger and more targets could be hit and considered as one target by the system. In order to clarify this drawback, these phenomena could be assumes as random variables and comparison will be done within the same layer.

\section{Horizontal Distribution within Depth Layers}

In two dimensional term, the distribution pattern by depth layer can be drawn in contour of $2 \mathrm{~dB}$ interval by ignoring any trivial observation (few observation for certain range of target strength value) (Figure 3a until d). As shown in the figures the values of target strength vary with their position and depth layers. In February, several patches having higher value of target strength lie in the near surface layer extending from North of Semarang to Masalembu Bank, while different pattern occurred in the deeper layer (42 to $62 \mathrm{~m}$ deep). In October, distribution of target strength seems to be more regular and consists of bigger targets than that of February. During this period, the size of fish or target generally tend to be bigger in the eastern part of the Java Sea following an east west axis. 

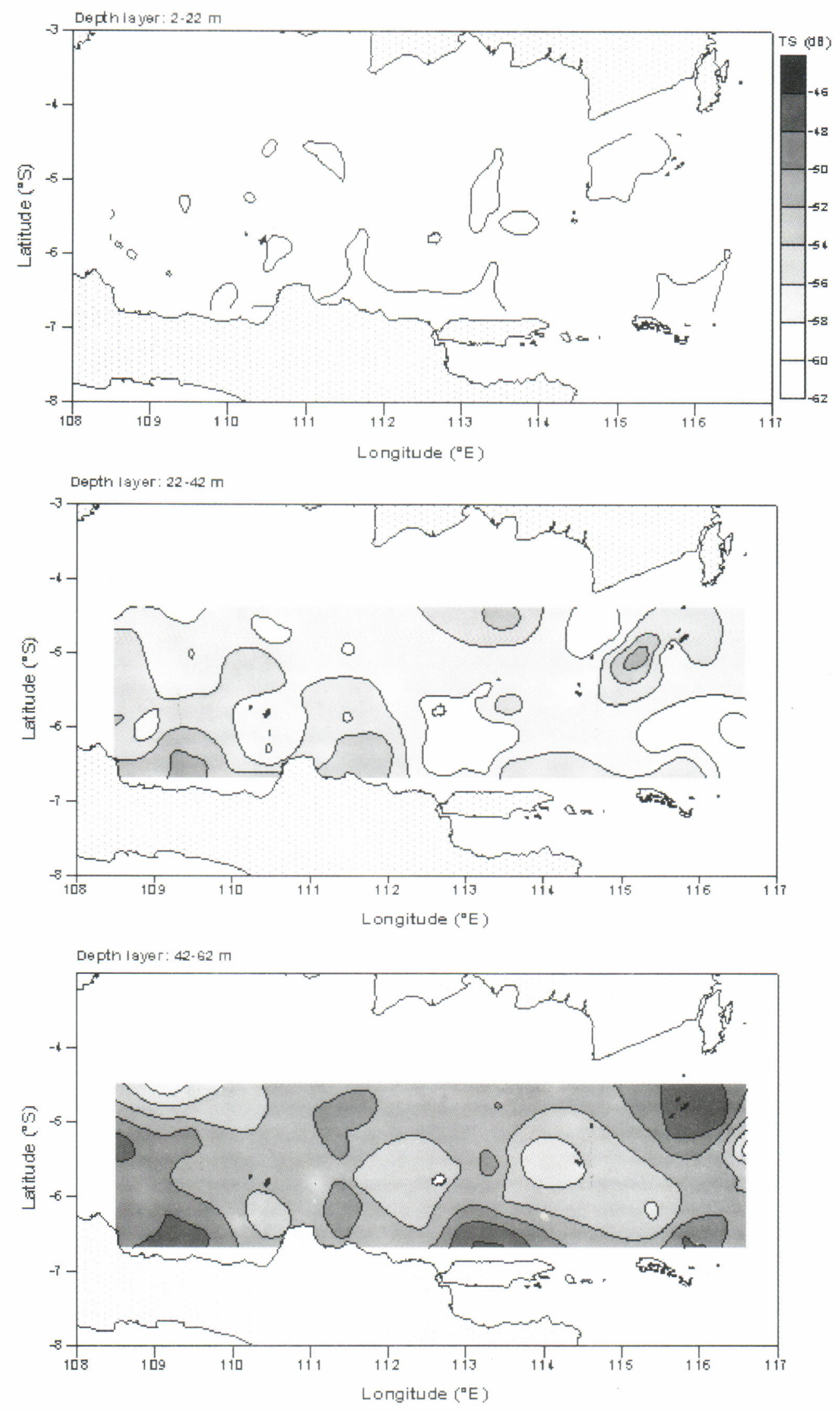

Figure 3a. Contour of target strength by depth layers on February. Remarks: Color scale is valid for all layers 

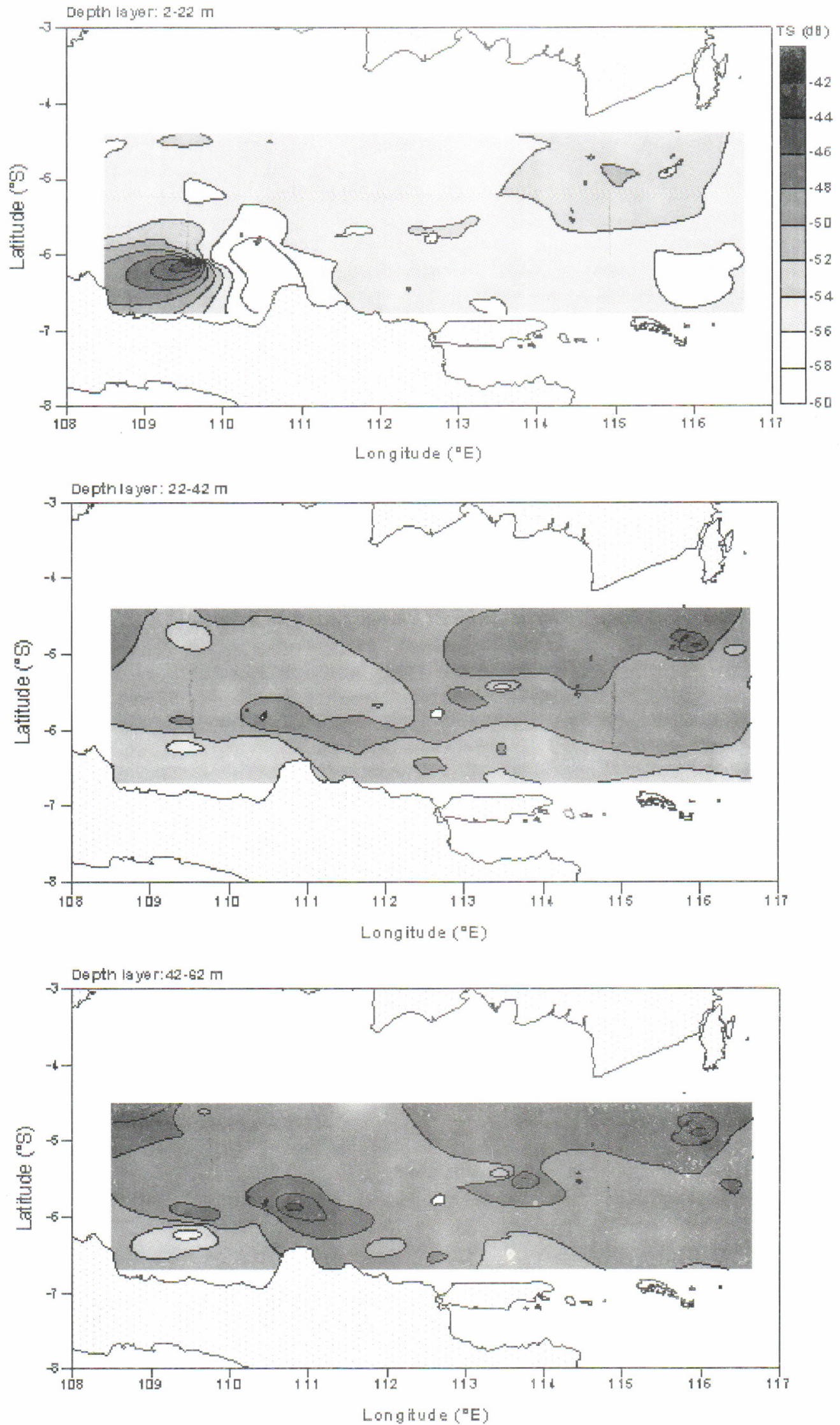

Figure 3b. Contour of target strength by depth layers on October. 
Depth layer: 2-12 m

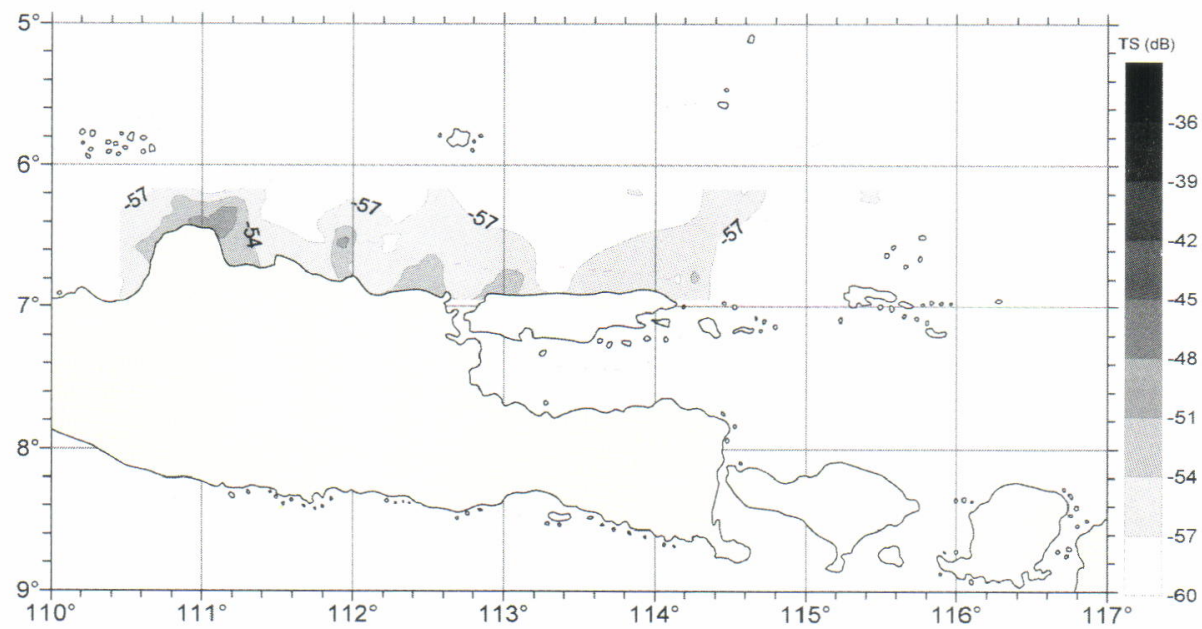

Depth layer: $22-32 \mathrm{~m}$

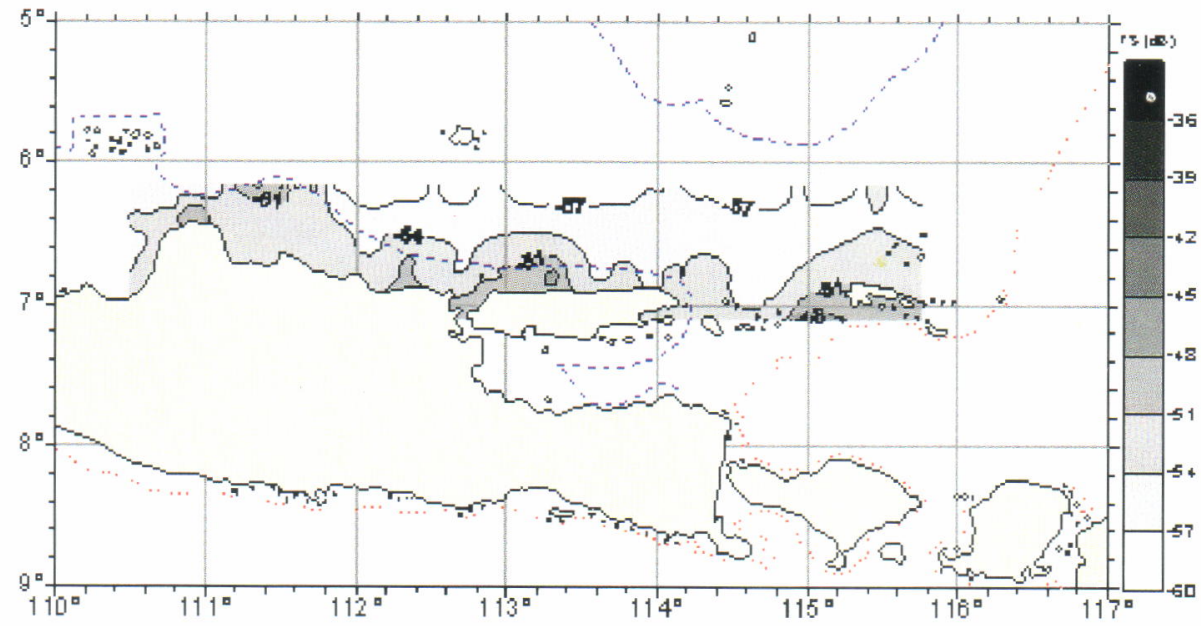

Depth layer: $42-52 \mathrm{~m}$

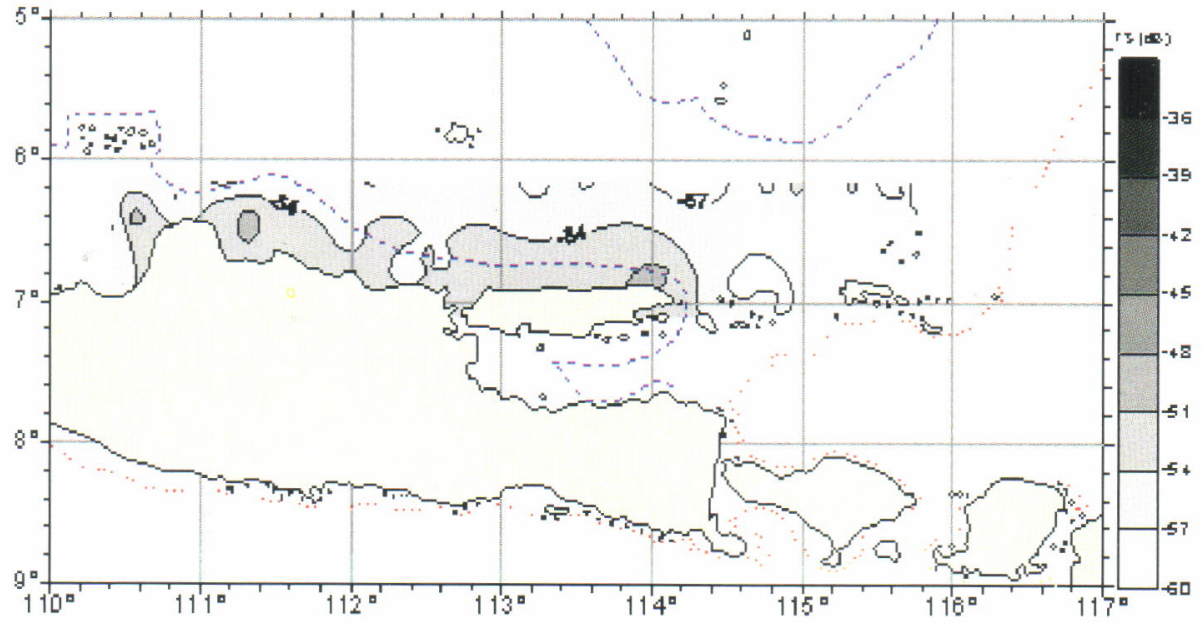

Figure 3c. Contour of target strength by depth layers on October. 
Depth layer: $2-52 \mathrm{~m}$

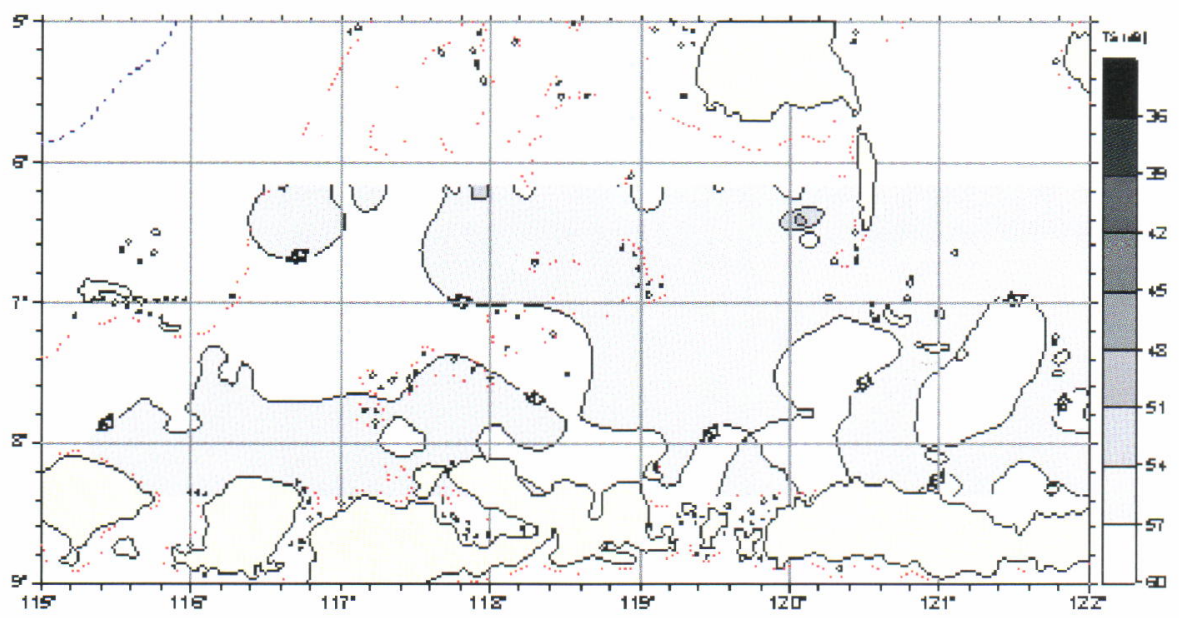

Depth layer: $52-102 \mathrm{~m}$

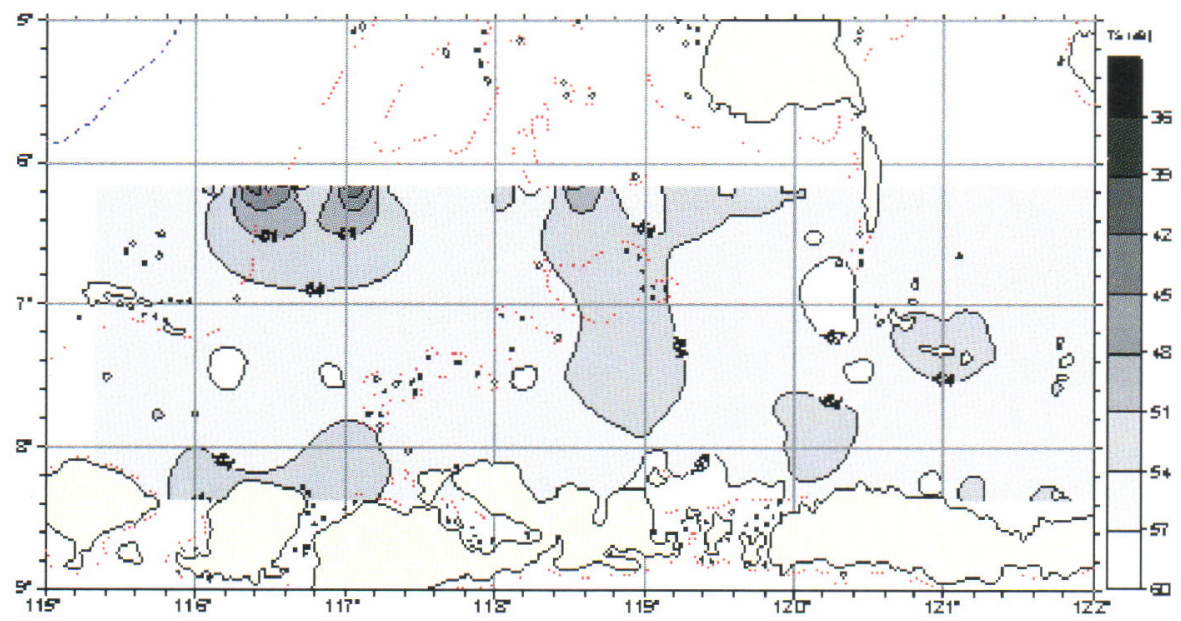

Depth layer: $102-152 \mathrm{~m}$

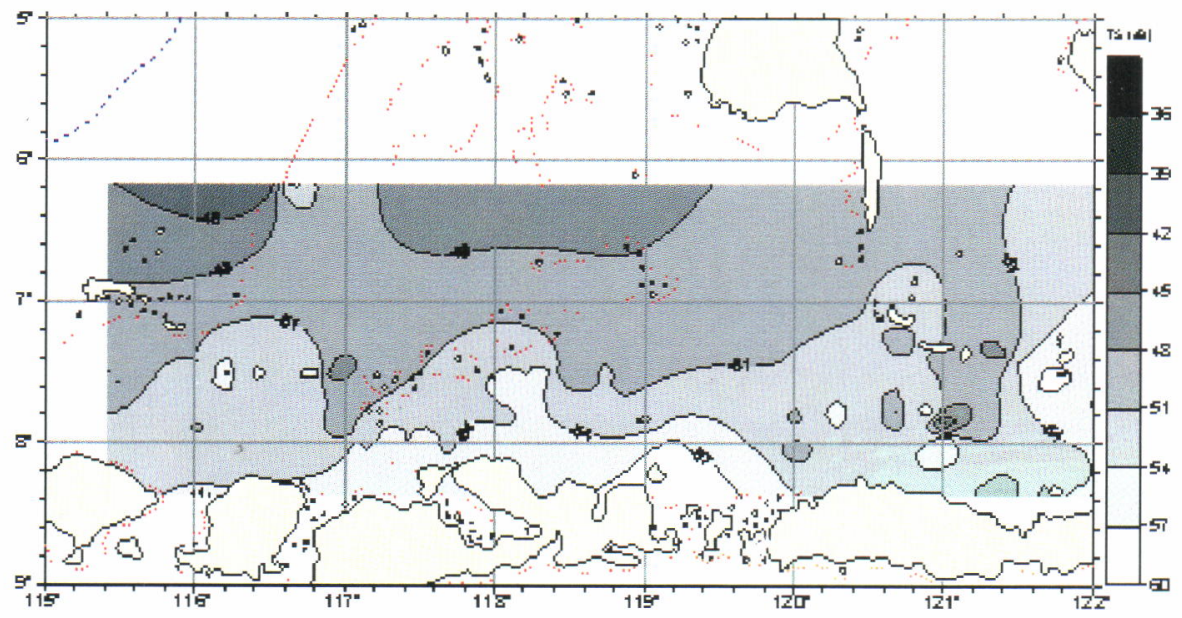

Figure 3d. Contour of target strength by depth layers on October 2005. 


\section{Relation to Salinity}

Relationship between mean target strength values and ambient salinity are evaluated by matching the target strength observations and salinity measurement of the nearest target strength stations. Possible influence of salinity on target strength at various depth layers can be evaluated by plotting the main modal values of target strength (i.e. for target strength are estimated as the mode of the distribution) versus salinity for all legs and straight transects from North coast of Central Java to Matasiri Bank (Figure 4a and b). In general, in relation to the salinity influence, the observations made in two dimensional coverage area can be represented by those of a straight transect as indicated by simillar pattern of the those figures.
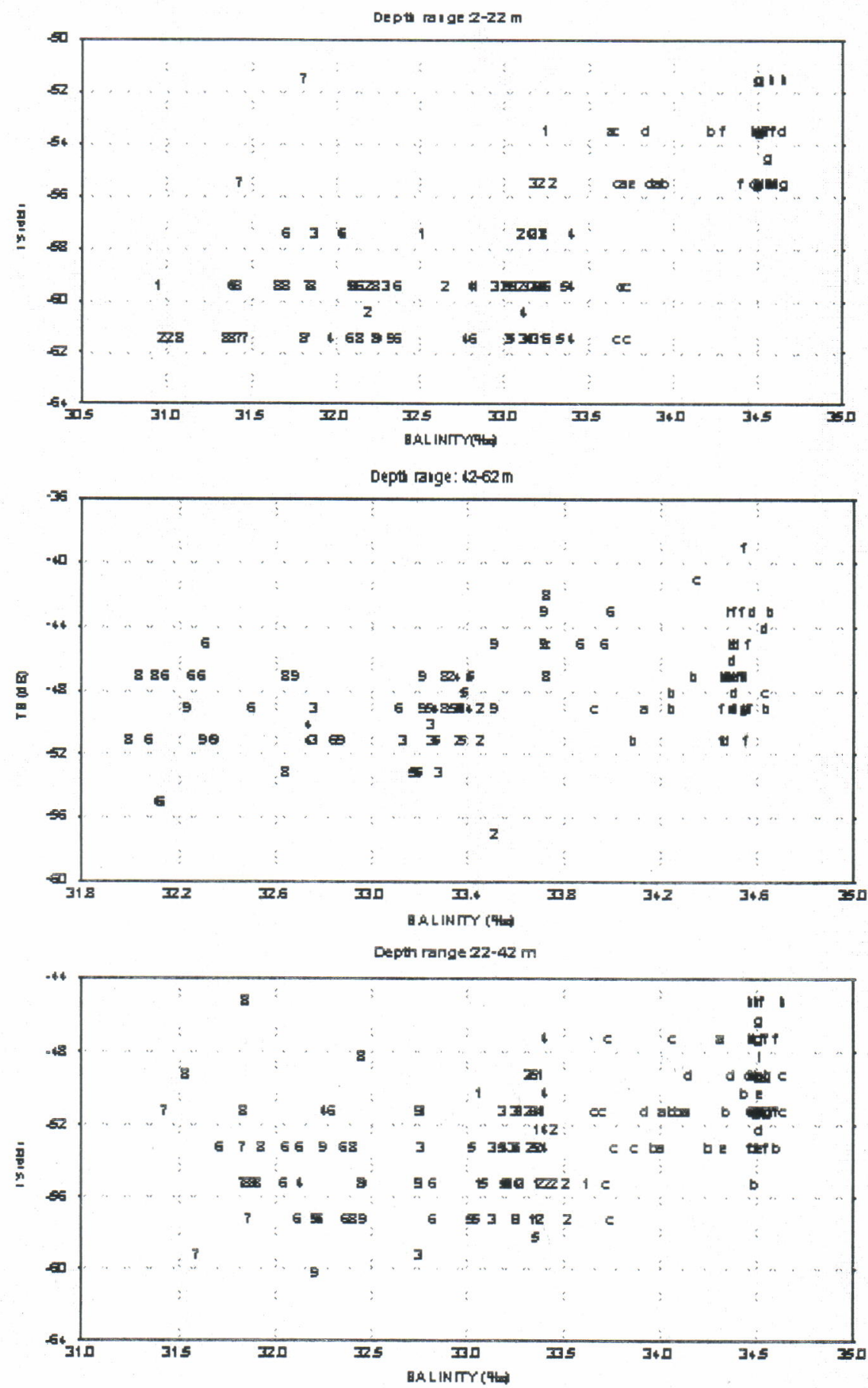

Figure 4a. Scatter plot of target strength versus salinity for various depth layers for all stations $(1,2, \ldots, 9$, and $a, b, \ldots, i$ are indicating longitude ranges of 108 to 109,109 to 110,116 to $117^{\circ} \mathrm{E}$ of February and October cruises respectively). 

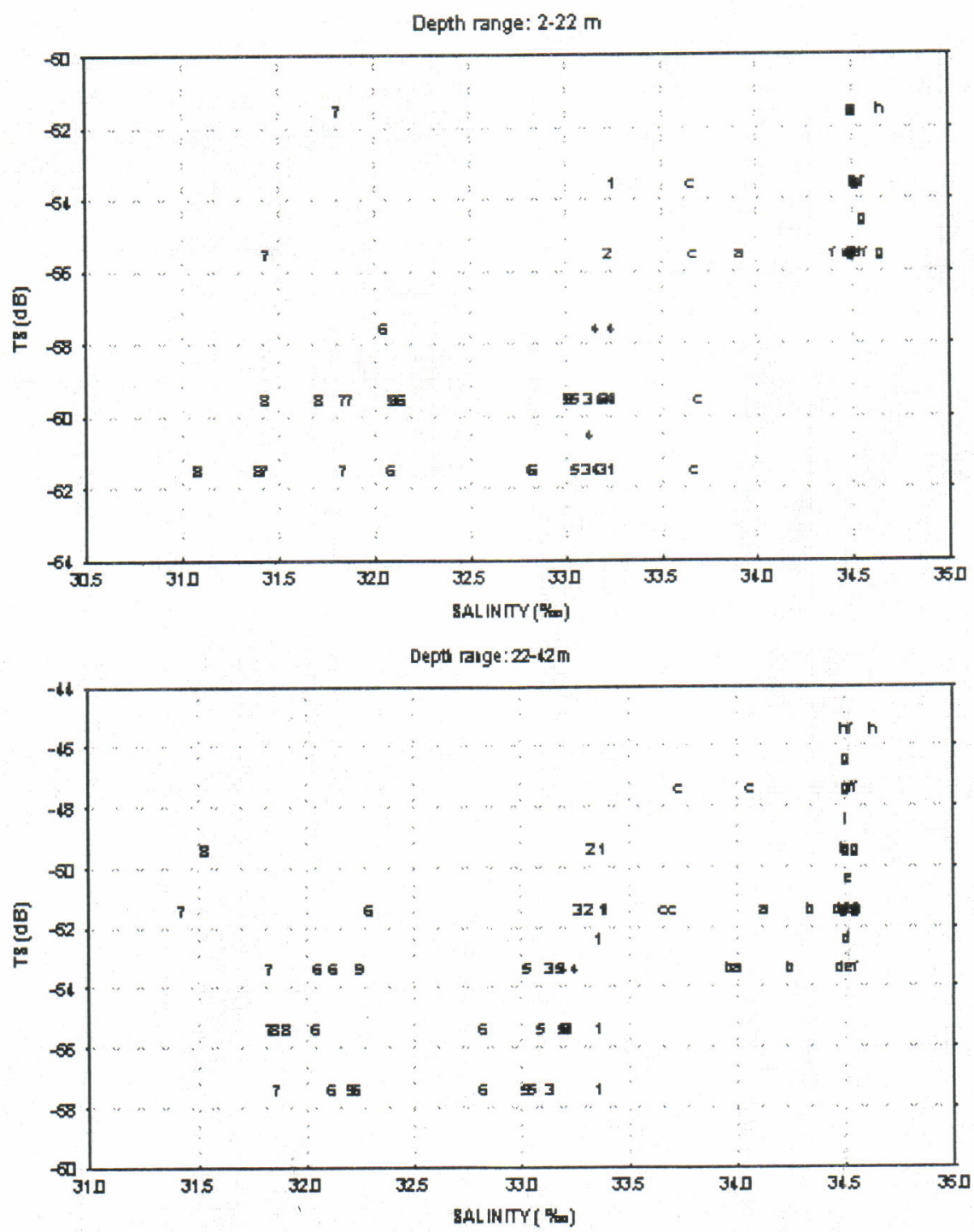

Depth range: $42-62 \mathrm{~m}$

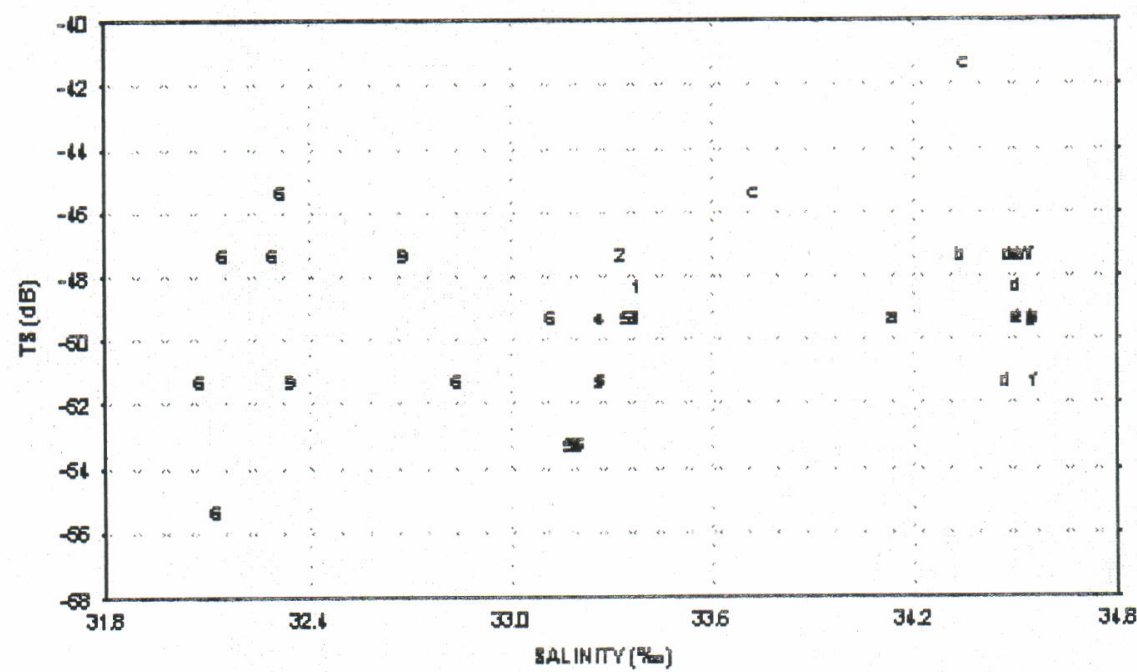

Figure 4b. Scatter plot of target strength versus salinity for various depth layers along straight transect Karimunjawa-Matasiri Bank (1, 2, .., 9, and a, b, .., i are indicating longitude 108 to 109, 109 to $110, \ldots, 116$ to $117^{\circ} \mathrm{E}$ of February and October cruises respectively). 
In this case, impact of salinity on target strength would be more complicated, due to possible link to water mass exchange with neighboring areas and different preference of each species staying in the subarea, as well. Different ranges of salinity value observed during the opposite seasons hamper comparison of this influence on target strength during the two periods of observation (Table 2).

Table 2.

Salinity values observed during February and October cruises

\begin{tabular}{ccccccc}
\hline \multirow{2}{*}{ Depth Range } & \multicolumn{3}{c}{ February } & \multicolumn{3}{c}{ October } \\
\cline { 2 - 7 } & Min & Max & Mean & Min & Max & Mean \\
\hline $2-12 \mathrm{~m}$ & 30.95 & 33.40 & 32.29 & 33.66 & 34.65 & 34.28 \\
$12-22 \mathrm{~m}$ & 31.43 & 33.40 & 32.65 & 33.63 & 34.64 & 34.30 \\
$22-32 \mathrm{~m}$ & 31.43 & 34.00 & 32.80 & 33.66 & 34.64 & 34.35 \\
$32-42 \mathrm{~m}$ & 31.83 & 33.62 & 32.92 & 33.73 & 34.63 & 34.41 \\
$42-52 \mathrm{~m}$ & 32.00 & 33.87 & 33.05 & 33.73 & 34.64 & 34.42 \\
$>52 \mathrm{~m}$ & 32.04 & 34.12 & 33.22 & 34.25 & 34.66 & 34.52 \\
\hline
\end{tabular}

Recall to the salinity average observed during the cruises and redrawn the salinity profile in these legs with superimposing to bottom contour (Sadhotomo, 2006) would give indirect interpretation of the relation of the distribution of salinity to target strength value. The range values of average salinity in February were wider than that of October. In February, higher value of salinity tended to occupy in the western part of the surveyed area, especially in the deeper layers; while in October the salinity was uniformly distributed with a slightly higher in eastern part. In term of east west direction, effect of longitude on salinity is markly shown in the tract located between $113^{\circ}$ and $116^{\circ} \mathrm{E}$ or around the Matasiri Bank (Figure 5) The influence of salinity to repartition of fish size was not so clear as that of depth and there was no significant preference of fish by size to the low value of salinity as demonstrated by regression on February observations (Table 3 ).

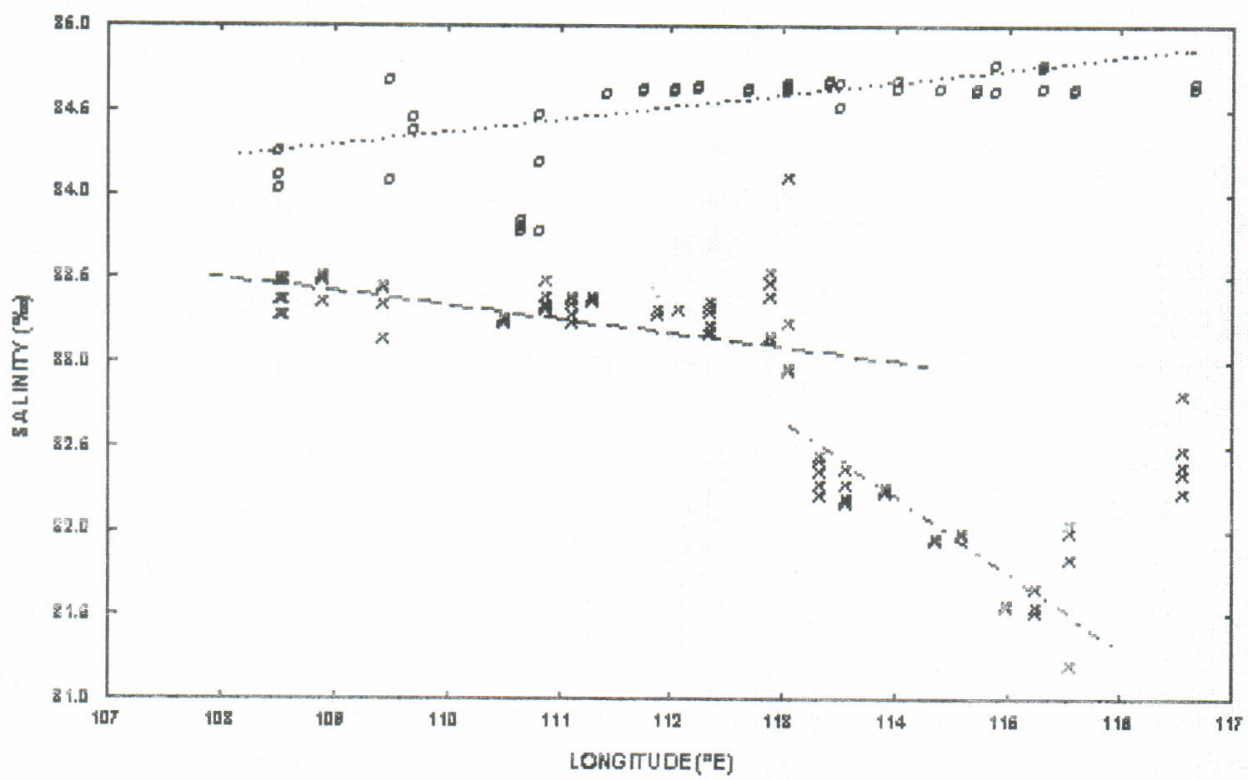

Figure 5. Relationship between salinity and longitude along the straight transect from north coast of Central Java to east part of Matasiri Bank.

Remarks: 0 and $x$ are indicate period of observation of October and February respectively, the lines are fitted by aye 
Table 3. Simple linear regression of target strength on longitude, salinity, and depth

TS=a+b salinity

\begin{tabular}{llll}
\hline \multicolumn{1}{c}{ Depth range } & Feb.1994 and Oct. 1993 & \multicolumn{1}{c}{ February 1994 } & \multicolumn{1}{c}{ October 1993 } \\
\hline $2-32 \mathrm{~m}$ & $\mathrm{a}=-122.9 ; b=1.94 ; r=0.66$ & not significant, $r<0.1$ & $a=-178.0 ; b=3.59 ; \quad r=0.55$ \\
$32-52 \mathrm{~m}$ & $a=-115.1 ; b=1.81 ; r=0.57$ & not significant, $r<0.1$ & $a=-148.9 ; b=2.81 ; \quad r=0.37$ \\
$>52 \mathrm{~m}$ & $a=-113.6 ; b=1.95 ; r=0.50$ & $a=-123.4 ; b=2.25 ; r=0.44$ & $a=-572 ; \quad b=15.23 ; r=0.37$ \\
All range & $a=-146.6 ; b=2.8 ; \quad r=0.53$ & $a=-149.2 ; b=2.86 ; r=0.40$ & $a=-256.6 ; b=5.90 ; \quad r=0.41$ \\
\hline
\end{tabular}

TS $=a+b$ longitude

\begin{tabular}{|c|c|c|c|}
\hline Depth range & June 1992 & February 1994 & October 1993 \\
\hline $2-32 \mathrm{~m}$ & not significant, $r<0.1$ & not significant, $r<0.1$ & $a=-104.2 ; b=0.43 ; r=0.42$ \\
\hline $32-52 m$ & $a=-94.9 ; b=0.40 ; r=0.29$ & not significant, $r<0.1$ & $a=-97.9 ; \quad b=0.41 ; r=0.45$ \\
\hline$>52 \mathrm{~m}$ & $\begin{array}{l}\text { not significant, unclear } \\
\text { pattern }\end{array}$ & $a=-127.5 ; b=0.61 ; r=0.41$ & not significant, $r<0.1$ \\
\hline All range & $a=-22.4 ; b=-0.26 ; r=0.21$ & $a=-94.9 ; b=0.35 ; r=0.18$ & $a=-94.3 ; \quad b=0.38 ; r=0.23$ \\
\hline
\end{tabular}

$T S=a+b_{1}$. salinity $+b_{2}$ longitude $+b_{3}$ depth

\begin{tabular}{|c|c|c|c|c|c|}
\hline \multirow{3}{*}{$\begin{array}{l}\text { Date } \\
\text { February } 1994 \text { and } \\
\text { October } 1993\end{array}$} & \multicolumn{2}{|c|}{$\begin{array}{l}\text { TS }=a+b_{1} \text { salinity }+b_{2} \\
\text { longitude }+b_{3} \text { depth }\end{array}$} & \multicolumn{2}{|c|}{$\begin{array}{c}\text { TS }=a+b_{1} \text { salinity } \\
+b_{2} \text { longitude }\end{array}$} & \multirow{3}{*}{$\begin{array}{c}\text { TS }=a+b_{1} \text { deptr } \\
a=-60.9 ; b=0.22 ; r=0.81\end{array}$} \\
\hline & $a=-131$ & $r=0.88$ & $a=-197.3$ & $r=0.57$ & \\
\hline & $\begin{array}{l}b_{1}=1.7 \\
b_{2}=0.12 \\
b_{3}=0.19\end{array}$ & $\begin{array}{l}\beta_{1}=0.33 \\
\beta_{2}=0.6 \\
\beta_{3}=0.71\end{array}$ & $\begin{array}{l}b_{1}=2.79 \\
b_{2}=0.45\end{array}$ & $\begin{array}{l}\beta_{1}=0.53 \\
\beta_{2}=0.22\end{array}$ & \\
\hline February 1994 & $\begin{array}{l}a=-48.2 \\
b_{1}=0.02 \\
b_{2}=-0.14 \\
b_{3}=0.23\end{array}$ & $\begin{array}{l}r=0.88 \\
\beta_{1}=0.003 \\
\beta_{2}=-0.07 \\
\beta_{3}=0.89\end{array}$ & $\begin{array}{l}a=-256.2 \\
b_{1}=3.72 \\
b_{2}=0.7\end{array}$ & $\begin{array}{l}r=0.52 \\
\beta_{1}=0.51 \\
\beta_{2}=0.35\end{array}$ & $a=-62.6 ; b=0.22 ; r=0.87$ \\
\hline October 1993 & $\begin{array}{l}a=-148.3 \\
b_{1}=2.46 \\
b_{2}=0.06 \\
b_{3}=0.17\end{array}$ & $\begin{aligned} r & =0.85 \\
\beta_{1} & =0.17 \\
\beta_{2} & =0.03 \\
\beta_{3} & =6.78\end{aligned}$ & $\begin{array}{l}a=-256.2 \\
b_{1}=5.93 \\
b_{2}=0.008\end{array}$ & $\begin{array}{l}r=0.41 \\
\beta_{1}=0.41 \\
\beta_{2}=0.04\end{array}$ & $a=-57.6 ; b=0.18 ; r=0.83$ \\
\hline
\end{tabular}

As can be seen in the plots, there were three groups of points of observations separated by different range of salinity. One group was a collection of points with narrow range of salinity and higher average of target strength that observed in October. The second one was a group of observations with range of salinity 32.5 to $33.5 \%$ and the third cluster was those of salinity value less than $32.5 \%$. More detailed attention could be taken for the third cluster of observations in longitude range of 113 to $116^{\circ} \mathrm{E}$ or above Matasiri Bank. In this place, some points of high target strength values were obviously observed at relatively low salinity and the salinity value decrease as the position shift to east direction.

\section{Influence of Longitude}

Plotting of target strength (modal values) of each station lied in the transect from Karimunjawa to Matasiri as depicted in Figure 6 and 7, would be valuable for describing that phenomena. Strong influence of the longitude on target strength was clearly shown by observations made during October cruise (indicated by the slope of tendency lines). In general, the value of target strength increases as the position move to east direction, except for the deeper layer (52 to $62 \mathrm{~m}$ deep layer; L5) during northwest monsoon (February and June) where the salinity is higher. 
Karimunjawa Is-Matasiri (October 2005)

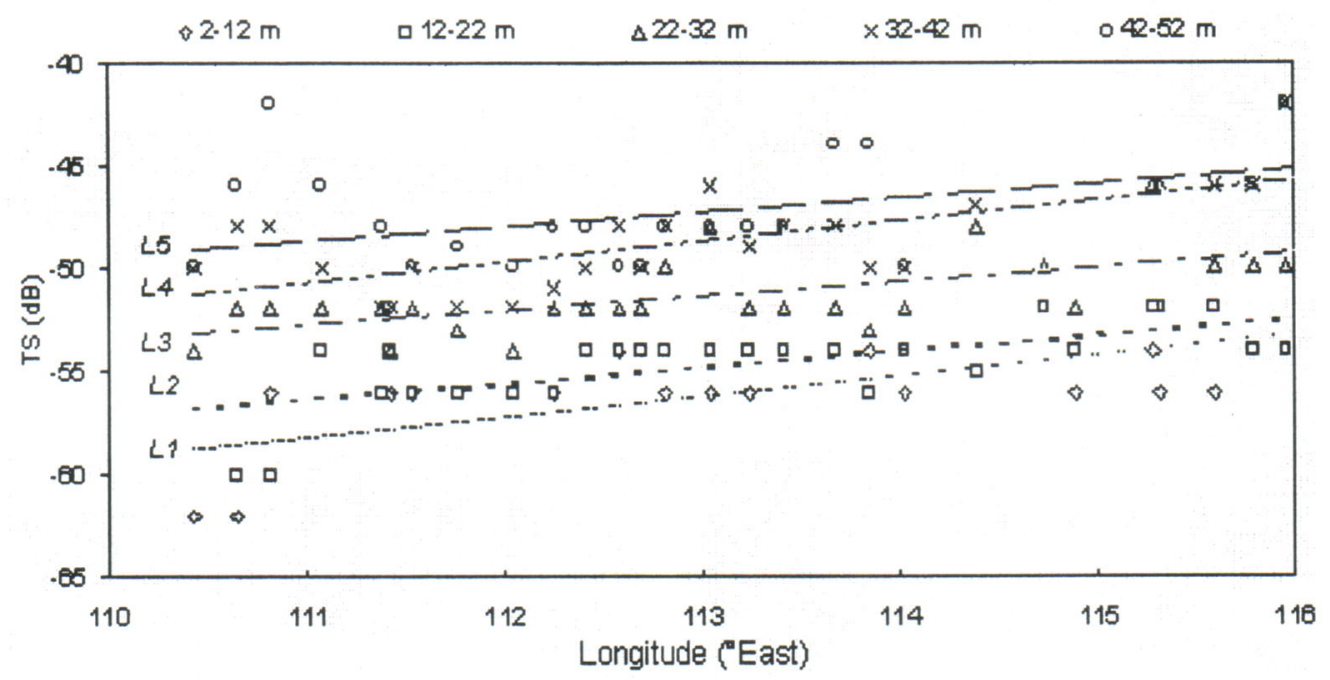

Karimunjawa Is-Matasiri (February 1994)

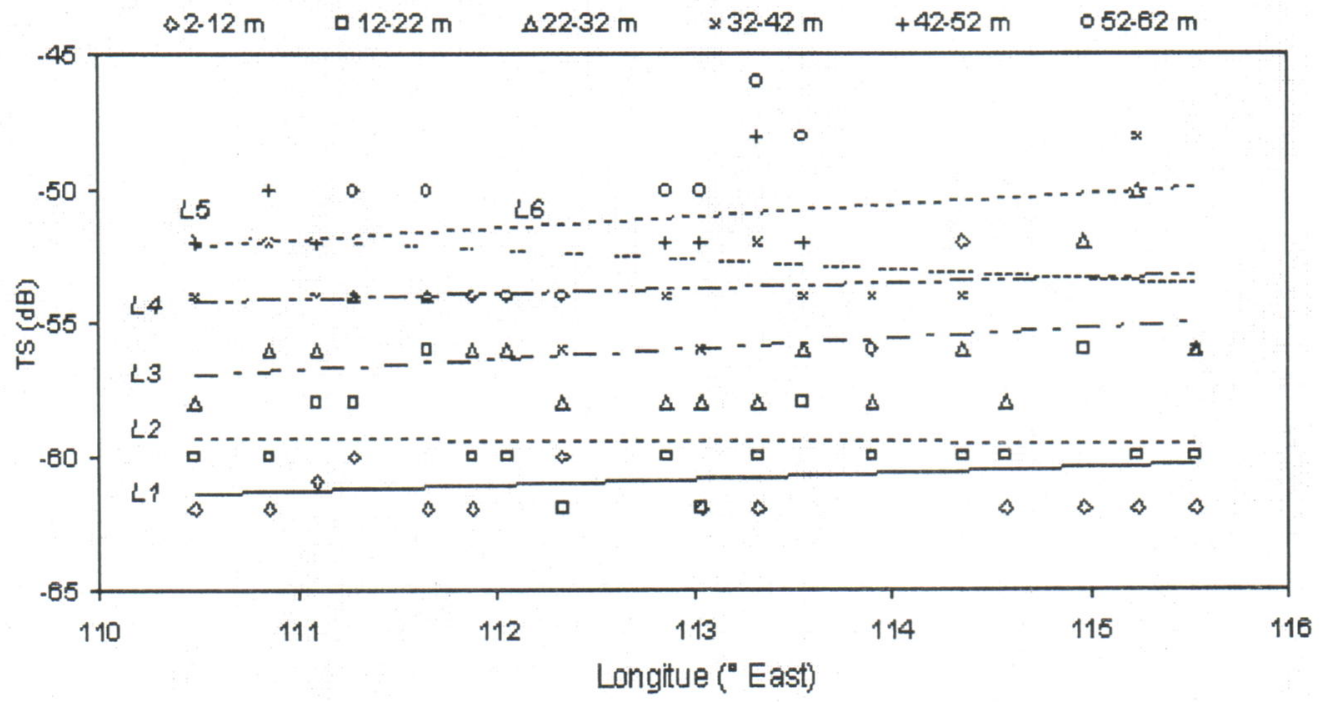

Figure 6. Target strength versus longitude at various depth layers along the transect line from Karimunjawa to Matasiri Bank ( $L 1, L 2, L 3, \ldots$, are linear trend lines of 2 to $12 \mathrm{~m}, 12$ to $22 \mathrm{~m}, 22$ to $32 \mathrm{~m}$ depth layer respectively. 


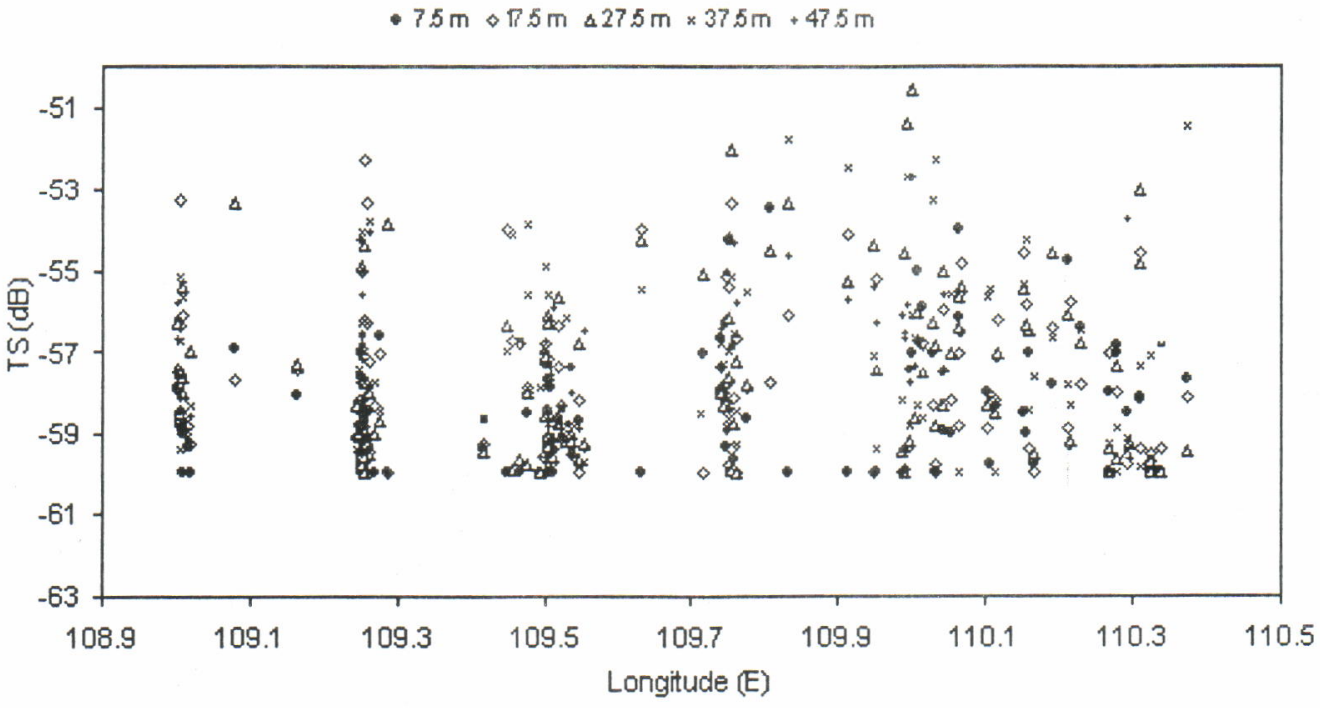

North coast of Madura-Flores (October 2005)

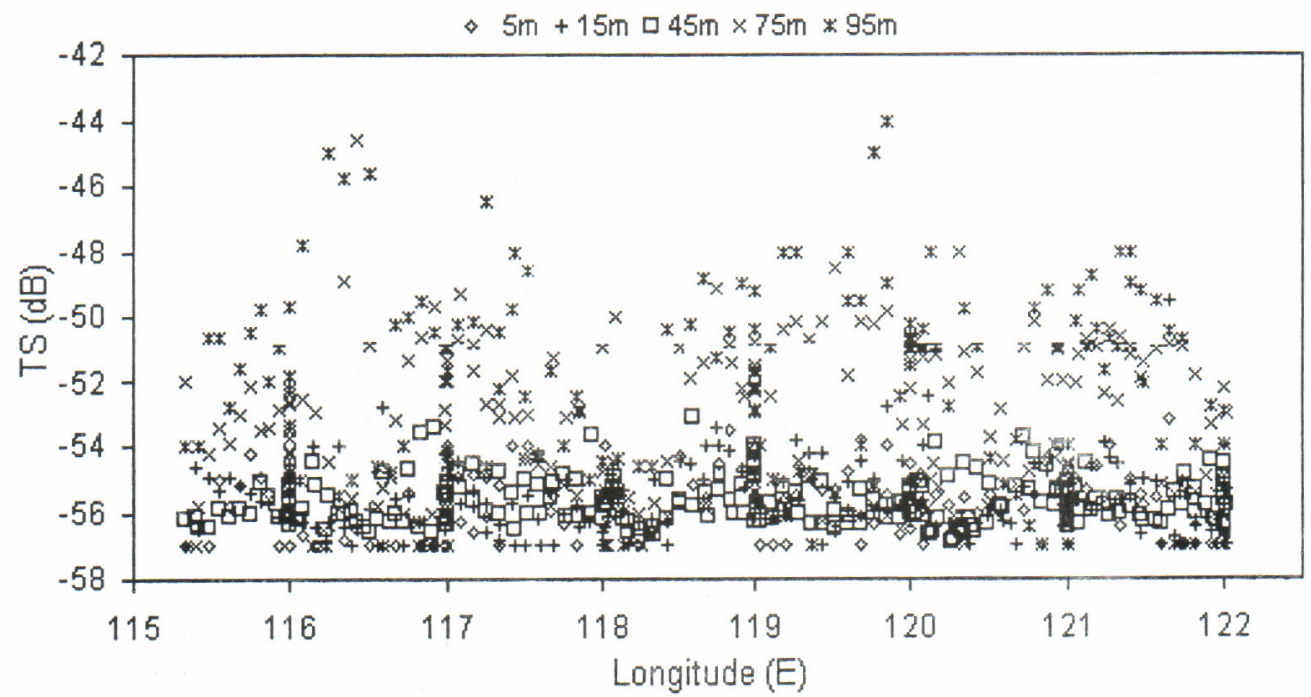

Figure 7. Scatter diagram of relationship between target strength and longitude observed on Oktober and December 2005.

Very weak relationships are apparently shown by the regression coefficient and the pattern of points in the plots, but adding other variables to the regression apparantly result a better fitting (Table 3 ), but an attention should be taken due to a possible occurence of colinearity, i.e high correlation between salinity and longitude as demontrated in Figure 5 . This analysis could be considered as first step to explore the relationship between target strength and other factors by ignoring diagnosis in the regression analysis. As indicated by simple regression of target strength on salinity and longitude, contribution of salinity in explaining this relation was higher than its longitudinal position during February and October cruises.

Theoretically and empirically, the echo returned from a group or a single fish was influenced by their behaviour and the morphology of fish. Orientation and tilt angle of fish and the presence of swimbladder have been the object of numerous studies (Foote, 1980; McClatchie et al., 1996; Foote \& Ona, 1985a); and comprenhensive review of Midttun (1984) for orientation impact on target strength. 
Several studies indicated that highly variation of target strength was influenced by pitch angle of the fish, where maximum value tends to be function of zero or near zero value. For example, the difference between target strength values observed at zero and 20 degree of tilt angle at various depth can attain more than $20 \mathrm{~dB}$ for the range of all target strength value $\sim 35$ to $65 \mathrm{~dB}$ (as depicted in the graph of Mukai and Foote 1997). Similar tendency has been given in several studies.

The importance of the presence of swimbladder has been commonly aggreed as another factor influencing on the value of target strength. It can be shown that high proportion of the backsacttered echo was contributed by swimbladder (Mukai \& lida, 1996), of which, theoretically, the shape of swimbladder also give a particular influence on target strength value (McClatchie et al., 1996).

The wide range of target strength values collected by the system may be engendered by non technical reason such as tilt angle of the target. Variation of target strength observations on Decapterus russellii was demonstrated in cage experiment conducted by Cotel \& Petit (1995). Their results indicated the wide range of target strength observation for a single fish, but the distribution shape appeared to be close to normal with low standard deviation and the variance were clearly independent from the estimated means. On the other hand, a comparison of the estimated target strength values derived from different target strength fish length relationship of two in situ observations indicated that the difference between estimate values of the mean maximum dorsal target strength for $10 \mathrm{~cm}$ long of herring to be 2.7 to $4.6 \mathrm{~dB}$, and it would be lower as the fish length increase (Halldőrsson \&.Reynisson, 1983).

It means that variation of estimates for $D$. russellii is slightly higher than those for herring, but it can be considered to be consistent for possible size range for this study with underlying assumption of the same variation of target strength measurement can be applied for our in situ observations. For this reason, the same setting was applied in that ex situ experimental. However, not all of the data did exhibit a symmetric distribution, thus, the use of modal value was more robust to avoid existing extreme values (i.e. very high and low values of the frequency distribution) than arithmethic mean. This procedure could be expected to be able to eliminate the impact of noises generated by the system and fish orientation.

In relation to the system used in data collection and the target, possible bias may be existed by acceptance of echo coming from multi-targets as the Biosonic system interface always deliver the result regardless whatsoever the quality of the output data. These biases existed in favour of posistive interference of overlapping echo that lead to an overestimate of target strength (Soule et al., 1996). An actual demontration on bias generated by the aggregated anchovy (Engraulis capensis) being measured at $38 \mathrm{kHz}$ was presented by Barange et al. (1996). This type of bias lead to produce a stronger modal distribution (with higher mean) of target strength. However, the current system often mistakenly accept multiple echo and analysing them as single echo, when resolution densities are exceeded (Soule et al., 1996).

In general, target strength observations are designed for low density of fish that enable the system to screen out only single targets hit inside the coverage beam angle. If the biases mostly resulted from composit targets, the above statement would relate to the position of highly aggregated shoals during the period of observations. Recall to the first acoustic evaluation (Petit \& Potier, 1995; Sadhotomo, 2002) that schooling size in the Java Sea was relatively small, one could expect that probability of accepting multiple echo was low especially during February cruise.

Ignoring a possible acoustical artifact factor will lead to a conclusion that the depth was the most dominant factor determining the repartition of fish size in the Java Sea. The result clearly corroborated a common preference of large pelagic fish to stay in the deeper layer. For the most demersal fish in the Java Sea, this tendency had been well proved by evaluating trawl survey data (Beck \& Sudrajat, 1979).

Due to the lack of swimbladder or very small size, this tendency may aiso be valid for smali pelagic species. The target strength of fishes with swimbladder tended to decrease with increasing depth. The swimbladder contract concentrically under increasing pressure (with increasing depth), the volume and cross sectional area reduction was automatically followed by target strength. Morever, the major contribution to scattering target strength coming from fish was due to the swimbladder. Target strength of swimbladder was always greater than that of the fish body (Mukai \& lida, 1996; Foote, 1980). But, as the frequency increases, contribution of the fish body to the scattering sound was more important than the swimbladder, and for a given frequency, the fish body was the dominant scatterer for larger fish (Ye \& Farmer, 1996). Using an acoustical frequency of $200 \mathrm{kHz}$, it was found that forward scattering of fish body dominated for the fish whose length was longer than $11 \mathrm{~cm}$. Based on their frequency range used in their experimental, one could expect that at 120 $\mathrm{kHz}$ as used in this study, the fish body was more important for the common size in the Java Sea. 
Two conditions of activity can be regarded as another factor eliminating the influence of swimbladder in this study. The first was compression of swimbladder when the fishes moving down to the deeper layer. The second one was a stable condition of the swimbladder when they are staying in the deeper swimming layer, of which its impact on target strength would be neglectable. Therefore, no influence of swimbladder could be notice, or at least, it can be assumed that its influence was considerably random, and the increase of target strength value with depth would be merely affected by fish size.

In term of east west direction of size gradient, target strength distribution value did not exactly confirm the previous investigations of Hardenberg (1938); Sadhotomo \& Potier (1995). The length data collected from fishery used in those studies represent only some zones in the Java Sea area, i.e. the fishing zones, while the coverage of the target strength data was more continueous and includes unfished grounds.

As mentioned previously, direction of water mass exchange with other areas and its bathymetry trend of the Java Sea are mostly in east west axis. Linked with hydrographical and morphological feature of the area, and possible direction of migration of the dominant species, the spatial influence on fish size should not be sought as an independent factor influencing the target strength pattern.

Return to the two dimensional coverage of observations, one could classify distribution pattern of big target (say higher than -48 decibel) into two categories:

1. Sporadic distribution where the bigger targets tended to concentrate in some places.

2. Extensive distribution where the bigger target distributed homogeneously over large area.

Based on this classification, it was interesting to evaluate the target strength distribution in certain part of the Java sea, i.e. in west part of the coverage area (north coast of central Java), Matasiri Bank and in the near continental slope, by considering hydrological factor of the Java Sea. It could be assumed that different pattern of targets strength distribution may be exhibited by different species or the same species of different cohorts.

During rainy season, dilution impact on salinity distribution did not present the same aspect as those of dry season. Irregular pattern of salinity gradient as indicated by north south pattern of the near surface isohaline and west east pattern in salinity profile along transect in the middle of the Java Sea, may play significant role in influencing distribution of target strength.
Response of fish to this condition is to form an appropriate repartition by size and species. During this time, certain oceanic and highly migrant species, such as Decapterus macrosoma and $D$. russellii probably occupy in the deeper layer of the west part of the Java Sea (with salinity more than $32 \%$ ), while the other still stay in Matasiri Bank and adjacent area before migrating to east direction. However, more turbid and less saline water in the southern part of the area were not favorable condition for this type of species.

During rainy season, strong influence of dilution by fresh water from Kalimantan may reach the middle part of the Java Sea. This process may not perfectly work in the middle and southern part as the distance are farther from the coast line (especially from Kalimantan). The occurence of some enclave of slightly higher saline water mass may still exists somewhere and sparsely distributes in this subarea. Certain species may be trapped inside this water mass and detected as patchy pattern of higher target strength contour in the west part of the area.

In October the gradient of salinity distribution was clearer than that of February. During this period, penetration of oceanic water from eastern region had reached yet the middle part of the Java Sea. Comparing the pattern of target strength and salinity revealed that the target strength patterns during this season tended to follow salinity gradient in the pattern of second stratum as mentioned above, rather than east west axis direction.

\section{CONCLUSION}

Size gradient of pelagic fish in the Java Sea tended to spatially follow direction from north coast of Central Java to southern Macassar Strait (Lumu-lumu Bank, Laut Island) or west northeast axis, while in the southern part (north coast of Madura-Flores), this pattern was not apprent and tended to be random. It was mainly due to internal migration scheme of the older fishes to the eastern areas and immigration flux during the southeast monsoon. The longitude and fish size relationship related to the phenomena of salinity gradient being generated by seasonal variability that simultaneously occur with migration. The migration activity inside the Java Sea syncroneously follow monsoonal cyle, resulting gradient of size in the west east axis direction in the middle part of this area.

Depart from the above statement, the migratory scheme is proposed in this study with a possibility of mixing of subpopulations of migrant species or at least, for different progeny (particularly the dominant species, Decapterus spp.) from the north west and east areas. 
These can be considered as the important point in understanding the Java Sea pelagic fish community, especially in relation to the definition of population unit for the highly migratory species. Based on common phenomenon that the seasonal change of salinity plays a significant role in determining the staying duration of the immigrant in the Java Sea, the main pelagic species in the Java Sea spent part of their life in several zones inside this area and the rest in neighboring waters areas.

\section{ACKNOWLEDGEMENTS}

This paper was part of inhouse program title: Research of spatial dynamic and fishery resources in the Java Sea, Makassar Strait, and Flores Sea, F.Y. 2005.

\section{REFERENCES}

Barange, M., Hampton I., \& Soule, M. 1996. Empirical determiniation of in situ target strength of three loosely aggregated pelagic fish species. ICES Journal Marine Science. 53. 225-232.

Beck, U. \& Sudradjat, A. 1979. Variation in size and composition of demersal trawl catches from the north coast of Java with estimated growth parameters for three important food fish species. Special Report. Contribution of the Demersal Fisheries Project. 4. Marine Fisheries Resources Inst. GTZ.

Cotel, P. \& Petit, D. 1995. Target strength measurement on three pelagic fishes in the Java Sea. The Fourth Asian Fishery Forum. Beijing.

Durand, J. R. \& Petit. D. 1995. The Java Sea environment. In M. Potier \& S. Nurhakim (eds). Seminar on the Biology, Dynamics, and Exploitations. Java Sea Pelagic Fishery Assessment Project. Jakarta.

Foote, K. G. 1980. Effect of fish behaviour on echo energy: The need for measurement of orientation distribution. Journal CIEM. 39 (2).193-201.

Foote, K. G. \& Ona, E. 1985. Swimbladder cross sections and acoustic target strengths of 13 pollack and 2 saithe. Fisk Dir. Skr. Hav. Unders. 18. 1-57.

Halldôrsson, O. \& Reynisson, P. 1983. Target strength measurement of herring and capelin in situ at Iceland. FAO. Fish. Rep. 300. 79-84.
Hardenberg, J. D. F. 1938. Preliminary report on a migration of fish in the Java Sea. Treubia. Deel 16. Afl. 2. 295-300 p.

McClatchie, S., Alsop J., Ye Z., \& Coombs, R. F. 1996. Consequence of swimmbladder model choice and fish orientation to tarfet strength of three New Zealand fish species. ICES. Journal Marine Science. 53. 847-862.

Midttun, L. 1984. Fish and other organisms as acoustics targets. Rapp. P.-v. Réun. CIEM. 184. 25-33.

Mukai, T. \& Foote, K. G. 1997. On the depth dependence of fish target strength. ICES. C. M 1997/FF: 7. Theme Session on Fisheries Technology.

Mukai, T. \& lida, K. 1996. Depth dependence of target strength of live kokanee salmon in accordance with Boyle's law. ICES Journal Marine Science Symposium Edition. 53. 245-248.

Ona, E. 1984. In situ observation of swimbladder compression in herring. ICES CM 1984/B: 18. 15 p.

Petit, D. \& Potier, M. 1995. Fishing strategies and tactics in the Javanese seiner fisheries. In Potier, M. \& Nurhakim, S. (eds). Seminar on the Biology, Dynamics and Exploitations. Java Sea Pelagic Fishery Assessment Project.

Potier, M. 1998. Pêcherie de layang et senneurs semi industriel Javanaise: Perspective historique et approche système. Thèse de Doctorat. University Montpellier II. $300 \mathrm{p}$.

Potier, M. \& Boely T. 1990. Influence de parametre de l'environnement sur la peche a la senne tournante et coulissante en Mer de Java. Aquatic Living Resources. 3. 193-205.

Potier, M. \& Sadhotomo, B. 1995. Trends in scad fishery of the Java Sea. The Fourth Asian Fisheries Forum. Beijing. October 1995.

Potier \& S. Nurhakim 1995.(eds). Seminar on the Biology, Dynamics, and Exploitations. Java Sea Pelagic Fishery Assessment Project. Jakarta.

Sadhotomo, B. 2002. Spatial dynamics of pelagic fish aggregation in the Java Sea based on hydro acoustics. Indonesian Fisheries Research Journal. 1 (7). 25-46 p. 
Sadhotomo, B. 2006. Review on the environmental of the Java Sea. Indonesian Fisheries Research Journal. 2 (12). 129-157p.

Sadhotomo, B. \& Durand J. R. 1997. General feature of the Java Sea ecology. Proceeding of Acoustics Seminar Akustikan 2. EU-AARD-ORSTOM. 43-54 p.

Sadhotomo, B. \& Widodo, J. 1994. Maximum yield estimates for scads fishery in the Java Sea? Procidding the Third Asian Fishery Forum. Singapore.
26-30 October 1992. Asian Fisheries Society. Manila. 274-276p.

Soule, M., Hampton, I, \& Barange, M. 1996. Potential improvements to current method of recognizing single targets with a split beam echo sounder. ICES Journal Marine Science. 53. 237-243.

Ye, Z. \& Farmer, D. M. 1996. Acoustic scattering by in forward direction. ICES. Journal Marine Science Symposium Edition. 53. 249-252. 
